\title{
Orígenes del trotskismo en Colombia: de los colectivos socialistas revolucionarios al Bloque Socialista (1971-1977)*
}

\begin{abstract}
Álvaro Acevedo Tarazona
Profesor titular de la Universidad Industrial de Santander (Colombia). Correo electrónico: tarazona20@ gmail.com. El autor es doctor en Historia de la Universidad de Huelva (España). Miembro de la Asociación Colombiana de Historiadores. Entre sus publicaciones recientes tenemos en coautoría: "Los maestros y las maestras de escuela en el Estado institutor: su profesionalización y vinculación a la burocracia del Estado Soberano de Santander, 1870-1885", Revista Colombiana de Educación No. 74 (2018) y “Una aproximación al poblamiento de la provincia Guane en las visitas de 1560 y 1572", Historia y Espacio. Vol. 13, No. 49 (2017). Entre sus temas de interés están: Comunicación, educación y movimientos universitarios.
\end{abstract}

\section{FrankLin Patiño Romero}

Afiliado institucionalmente a la Fundación Universitaria Colombo Internacional (Colombia). Correo electrónico: frankpatinoromero@gmail.com. El autor es Magister en Historia de la Universidad del Atlántico (Colombia). Entre sus publicaciones recientes tenemos: "De la oscuridad de las salas a las luces de la industria: un recorrido por los festivales de cine en Colombia", Cuadernos de Cine Colombiano No. 27 (2017). Entre sus temas de interés están: Izquierda política en Colombia, Historia del movimiento cultural en los años 70 en el Caribe colombiano, Historia de la izquierda en el Caribe colombiano.

Recibido: 20 de octubre de 2017

Aprobado: 26 de junio de 2018

Modificado: 3 de julio de 2018

Artículo de investigación científica

DOI: http://dx.doi.org/10.15648/hc.34.2019.4

* $\quad$ Este artículo forma parte del proyecto: "Una crónica de 1968 en Colombia. Live fast, die young" financiado por la Vicerrectoría de Investigación y Extensión (VIE) de la Universidad Industrial de Santander - UIS (Colombia).

Esta publicación está bajo una licencia Creative Commons Reconocimiento-NoComercial 4.0 
Orígenes del trotskismo en Colombia: de los Colectivos socialistas revolucionarios al Bloque Socialista (1971-1977)

\title{
Resumen
}

El artículo reflexiona acerca del surgimiento de una corriente de la nueva izquierda en Colombia, el socialismo revolucionario o trotskismo, a partir de los movimientos estudiantiles ocurridos en las universidades colombianas en los años setenta del siglo XX y en medio de un proceso más general que fue el surgimiento tardío de la nueva izquierda en Colombia, como parte de la crisis de la hegemonía del Partido Comunista y del estalinismo a nivel internacional.

Palabras clave: Trotskismo, socialismo revolucionario, Bloque Socialista, movimiento estudiantil, lucha armada

Beginning of trotskismo in Colombia: from the revolutionary socialists to the Socialist block (1971-1977)

\begin{abstract}
The article reflects on the emergence of a new left movement in Colombia, revolutionary socialism or Trotskyism, from the student movements that occurred in Colombian universities in the seventies of the twentieth century and in the midst of a more general process that was the late emergence of the new left in Colombia, as part of the crisis of the hegemony of the Communist Party and Stalinism at the international level.
\end{abstract}

Keywords: Trotskyism, revolutionary socialism, Socialist Bloc, student movement, armed struggle.

\section{Orígens do trotskismo na Colômbia: dos colectivos socialistas revolucionários ao Bloco Socialista (1971-1977)}

\section{Resumo}

O artigo reflete sobre o surgimento de uma corrente da nova esquerda na Colômbia, o socialismo revolucionário ou trotskismo, a partir dos movimentos estudantis que aconteceram nas universidades colombianas durante os anos setenta do século XX e em meio a um processo mais geral que foi o surgimento tardio da nova esquerda na Colômbia, como parte da crise da hegemonia do partido comunistas e do stalinismo no plano internacional.

Palavras-chave: Trotskismo, socialismo revolucionário, bloco socialista, movimento estudantil, luta armada. 


\section{Les origines du trotskysme en Colombie: des collectivités socialistes et revolu- tionnaires au Bloc Socialiste (1971-1977)}

\section{Résumé}

L'article propose une réflexion sur l'émergence du courant de la nouvelle gauche en Colombie: le socialisme révolutionnaire ou Trotskysme a été conçu comme réponse aux mouvements étudiants issus des Universités colombiennes pendant les années 1970 et s'associe à processus plus large de crise de l'hégémonie du parti communiste et du stalinisme au niveau international, qui constitue un des motifs expliquant l'apparition tardive de la nouvelle gauche en Colombie.

Mots clés: Trotskysme, socialisme révolutionnaire, bloc socialiste, mouvement étudiants, lutte armée.

\section{INTRODUCCIÓN}

En febrero de 1971, con la ocupación de la Universidad del Valle por parte de las Fuerzas Militares, se inicia una crisis universitaria que deviene en una serie de paros estudiantiles que se extenderán hasta octubre de 1972. En medio de este proceso, surgen varios colectivos políticos que tienen como coincidencia la idea de que esta movilización debe apuntar a fortalecer el proceso revolucionario y no limitarse a la lucha por el Programa Mínimo de los Estudiantes Colombianos. Estos colectivos se identifican con el socialismo revolucionario, en contradicción con la Juventud Comunista (Juco) del Partido Comunista Colombiano (PCC) ${ }^{1}$ y con la Juventud

$1 \quad$ El PCC es fundado en 1930 tras la disolución del Partido Socialista Revolucionario en el que se destacan dirigentes como Ignacio Torres Giraldo, María Cano y Tomás Uribe Márquez, que había protagonizado una serie de huelgas en el sector agroindustrial. Una parte de la dirección política formada en la Unión de Repúblicas Socialistas Soviéticas (URSS) cuestiona el accionar de esta organización y plantea la necesidad de crear un partido centralizado bajo la dirección política de Moscú. En los años treinta el PCC adopta la política de alianzas con sectores progresistas del liberalismo -Frente Popular-y apoya la llamada Revolución en Marcha de López Pumarejo. Para 1941 el PCC cambia su nombre a Partido Socialista Democrático bajo la influencia del dirigente del Partido Comunista estadounidense Earl Russell Browder, quien promueve la reconciliación entre los bloques capitalista y socialista. En 1947 en el V Congreso del PCC es expulsado el llamado browderismo y vuelve al nombre de PCC, sin romper su alianza con el Partido Liberal a tal punto que para las elecciones en las que es asesinado el caudillo popular Jorge Eliécer Gaitán, el PCC apoya al candidato oficial liberal, Gabriel Turbay. 
Patriótica (Jupa) del Movimiento Obrero Independiente Revolucionario $(\mathrm{MOIR})^{2}$, quienes veían en la movilización estudiantil una etapa de la lucha democrática. Pero a pesar de que los colectivos socialistas revolucionarios tuvieron cierta influencia en el movimiento estudiantil, hasta ahora han estado al margen de la historiografía sobre la izquierda política en Colombia que ha tenido como telón de fondo el desarrollo del conflicto armado.

Estas organizaciones que surgen como respuesta al régimen bipartidista llamado Frente Nacional y que harán parte del ascenso de las luchas estudiantiles a nivel global, que se había iniciado con la jornada de Mayo del 68 en París ${ }^{3}$, se adscriben a las corrientes internacionales de la izquierda política: por una parte, el estalinismo y el maoísmo que plantean la necesidad de una revolución democrática previa a la revolución socialista, para lo cual se requiere una política de alianzas con sectores progresistas de la burguesía nacional; y, por otra parte, el trotskismo ${ }^{4}$ que propone poner "a la ofensiva al proletariado y sus luchas anticapitalistas al mismo tiempo que se realizan las luchas democráticas de resistencia" de un proceso de movilización y de encuentros estudiantiles que propician la conversión de estos colectivos en una corriente política y, más adelante, en una formación partidaria. En estos encuentros, los colectivos socialistas revolucionarios no solo encuentran coincidencias frente a la coyuntura del paro estudiantil sino frente a la caracterización de los acontecimientos in-

2 Las principales investigaciones del campo maoísta en Colombia han sido realizadas en los últimos años por los historiadores Frank Molano y Álvaro Acevedo Tarazona. Molano escribió su tesis El imaginario maoísta (1965-1982). Como mentalidad revolucionaria en la izquierda colombiana y el artículo "El campo es leńa seca lista para arder. La Liga Marxista Leninista de Colombia, 1971-1982". Por su parte, Álvaro Acevedo Tarazona ha escrito el artículo "Ideología revolucionaria y sociabilidad política en los grupos universitarios maoístas de los ańos 60 y 70 en Colombia" y el libro Memorias de una época: el movimiento estudiantil en Colombia en los ańos sesenta y setenta del siglo XX.

3 Un panorama de lo que fue la conformación de una nueva izquierda en Colombia como parte de estos procesos internacionales, se puede ver en el libro del historiador Álvaro Acevedo Tarazona 1968. Historia de un acontecimiento. Utopía y revolución en la universidad colombiana.

4 Daniel Bensaid, en su libro Trotskismos, resume las tesis trotskistas en cuatro planteamientos: la teoría de la revolución permanente en oposición al planteamiento de Stalin de poder construir el socialismo en un solo país; la idea de un programa de transición que supere la contradicción entre propuestas reformistas y propuestas revolucionarias, abandonando la idea de una revolución por etapas; la lucha contra la burocracia, el autoritarismo y el partido único en favor de la pluralidad política; y la construcción de un partido internacional.

5 Bloque Socialista, Por un Partido Obrero Socialista. Tesis y documentos del Bloque Socialista (Bogotá, 1975). 
ternacionales que ocurren a mediados del siglo XX.

Paralelamente a las convocatorias del movimiento estudiantil, algunos de estos colectivos se reúnen para coordinar acciones y posiciones frente a la coyuntura y más adelante trabajarán por consolidar una organización política: el Bloque Socialista. Esta agrupación conformará, para finales de 1977, el primer partido trotskista en Colombia, en un proceso de discusión con otros colectivos socialistas como el Grupo Espartaco y la Unión Socialista Revolucionaria, sin lograr unificar a la totalidad de los socialistas revolucionarios en Colombia.

Teniendo en cuenta lo anterior, este trabajo se ha dividido en cuatro apartados. El primero es una revisión de la historiografía sobre el trotskismo en Colombia. En el segundo se muestra un panorama de estos colectivos como parte del proceso de emergencia de una nueva izquierda en Colombia. En el tercero se revisan las principales discusiones presentadas con las otras organizaciones políticas durante el paro universitario de 1971 y que llevan a la unificación del Bloque Socialista. Y en el cuarto apartado se abordan las divergencias programáticas, en particular la lucha armada y el centralismo democrático, que no permitieron la construcción de un proyecto político común.

\section{El tROTSKISMO EN LA HiSTORIOGRAFÍA COLOMBIANA}

En Colombia, las ideas trotskistas se difunden en el movimiento estudiantil como parte del proceso de conformación de una nueva izquierda, tras los triunfos revolucionarios de Cuba y Vietnam y de los acontecimientos de Mayo del 68. Para estos colectivos políticos, la lectura de los textos de Isaac Deutscher -El profeta armado: Trotsky, 1879-1921; El profeta desarmado: Trotsky, 1921-1929 y El profeta desterrado: Trotsky, 1929-1940se convirtió en un acercamiento inicial ${ }^{6}$, una característica de quienes se acercaban al socialismo revolucionario era buscar explicaciones de la realidad más complejas que las tesis que llegaban desde Moscú y Pekín. Rubén Jaramillo Vélez en su texto Colombia, la modernidad postergada

6 Entrevista a Édgar Ospina, militante del Bloque Socialista proveniente del Colectivo Los Comuneros, Cartagena. diciembre de 2015. 
hace un balance del desarrollo de las ideas marxistas en este país y referencia el surgimiento de grupos socialistas revolucionarios que acogen el trotskismo, recogiendo la visión de Mario Arrubla, autor del influyente texto Estudios sobre el subdesarrollo en Colombia, emprende en el año 1963 junto a Estanislao Zuleta la redacción de la Revista Estrategia y la frustrada conformación del Partido de la Revolución Socialista. Jaramillo en el capítulo 'Recepción e incidencias del marxismo en Colombia' hace referencia al trotskismo valorando su intención de hacer interpretaciones marxistas de la realidad del país más allá de los manuales y esquemas pro-rusos o pro-chinos. En 1991 aparece International trotskysm 1929-1985 A documented analysis of the movement de Robert J. Alexander, un texto enciclopédico que contiene un aparte sobre Colombia en el que se habla del surgimiento de un colectivo trotskista en los años 30 del cual no se tienen referencias y que podría ser algún desprendimiento del Partido Socialista Revolucionario surgido en Colombia en los años $20^{7}$.

En el año 2000, el Centro de Investigación y Educación Popular (Cinep) publicó Una historia inconclusa. Izquierdas políticas y sociales en Colombia, una serie de artículos sobre las corrientes de izquierda en el país, dedicando uno al trotskismo, escrito por la investigadora Martha Cecilia García: El presente es de lucha, el futuro socialista, en el que se hace un importante esfuerzo por sintetizar la experiencia trotskista en Colombia.

Recientemente Álvaro Acevedo Tarazona ha realizado un estudio sobre el surgimiento de la nueva izquierda en Colombia en el proceso de movilización estudiantil: 1968. Historia de un acontecimiento. Utopía y revolución en la universidad colombiana, así como varios trabajos acerca de las corrientes maoístas en Colombia. Frank Molano también ha realizado estudios sobre el maoísmo, en particular, El campo es leña seca lista para arder. La Liga Marxista Leninista de Colombia, 1971-1982. También fue publicado un artículo de Jesús Rafael Bolívar, "Una historia de los Comandos Camilistas", en la que por primera vez se hace un recorrido por la historia de uno de estos colectivos del campo del socialismo revolucionario en Colombia. También es importante el aporte de Martín Mangiantini

7 Robert J, Alexander International trotskysm 1929-1985. A documented analysis of the movement. (Durham: Duke University Press, 1991). 
con la investigación El exilio trotskista en Colombia (1976-1982) en el que muestra la llegada de los dirigentes del Partido Socialista de los Trabajadores de Argentina a Colombia y las repercusiones que tiene al interior del Bloque Socialista.

Pero en particular, por sus relaciones con el trotskismo en Colombia, nos interesa resaltar el caso de Argentina. En este país, ha sido Martín Mangiantini quien ha realizado los primeros estudios del trotskismo, en particular su texto El trotskismo y el debate en torno a la lucha armada. Moreno, Santucho y la ruptura del PRT. Para entender la historia del trotskismo en Colombia, este es un texto fundamental, pues la discusión acerca de la guerra de guerrillas atravesó las discusiones del socialismo revolucionario.

\section{LA NUEVA IZQUIERDA Y LOS COLECTIVOS SOCIALISTAS REVOLUCIO- NARIOS}

Para inicios del decenio de los setenta la hegemonía de la URSS sobre el movimiento revolucionario a nivel global ha entrado en crisis por varios acontecimientos de la Posguerra: el triunfo de la Revolución China en 1949, la celebración del XX Congreso del Partido Comunista de la URSS en 1956 en el que se cuestionan los crímenes cometidos por Stalin contra el Partido Bolchevique, el triunfo de la Revolución Cubana en 1959 y la irrupción del movimiento estudiantil de Mayo del 68 en Francia.

Surge entonces en Colombia, en especial en el movimiento estudiantil, un proceso complejo de conformación de la llamada nueva izquierda, que para los ańos sesenta cuestiona la hegemonía pro-soviética en el movimiento social. La organización embrionaria de esta nueva izquierda es el Movimiento Obrero Estudiantil Campesino (MOEC). La importancia del MOEC es que rompe con la hegemonía que hasta el momento había ejercido la Juventud Comunista y el Partido Liberal entre los estudiantes, dando como resultado el surgimiento de una diversidad de colectivos que se declaran seguidores de corrientes como el maoísmo ${ }^{8}$, simpatizantes de la Revolución Cubana o del socialismo revolucionario, para diferenciarse de los considerados reformistas.

8 Álvaro Acevedo Tarazona, 1968. Historia de un acontecimiento. Utopía y revolución en la universidad colombiana (Bucaramanga: Ediciones Universidad Industrial de Santander, 2017). 
Estas pequeńas agrupaciones del socialismo revolucionario -Grupo Espartaco, Crítica Marxista, Gaceta Obrera, Diario Latino, Comuneros, Liga Obrera Comunista, Comandos Camilistas, Unión Socialista Revolucionaria, Grupo Marxista Internacional- se encuentran en el Paro Estudiantil de 1971, coordinan sus acciones y apuestan por avanzar hacia la construcción de un proyecto político común. Al tiempo que se abordan las discusiones internacionales, y a diferencia de las colectividades que se adscriben a los distintos "modelos" de revolución, las corrientes que se identifican inicialmente como socialistas revolucionarias (por no compartir la idea de la revolución por etapas que plantean tanto pro-chinos como pro-soviéticos) intentan "volver" al marxismo, lo que implica hacer análisis del desarrollo capitalista en el país y a partir de los mismos expresar sus posiciones frente a la lucha de clases.

En el Paro Estudiantil de 1971, la Universidad del Valle fue el escenario inicial de confrontación y fue allí donde surgió Crítica Marxista, colectivo del que harán parte Eduardo Barragán, Ricardo Sánchez y Fernando Cruz Kronfly, entre otros. Crítica Marxista se convierte en Tendencia Socialista y después hará parte del Bloque Socialista que agrupa a varios de los colectivos socialistas revolucionarios. Pero este proceso de convergencia que mantienen estos colectivos al interior del movimiento estudiantil se enfrenta a la complejidad de su inserción en la organización internacional que agrupa a los trotskistas, la IV Internacional, atravesada por una lucha entre mandelistas y morenistas ${ }^{9}$. Las agrupaciones socialistas revolucionarias más importantes, que hicieron parte de este proceso, fueron las siguientes ${ }^{10}$ :

Grupo Espartaco: conformado en mayo de 1970 en Bogotá con el liderazgo de Libardo González, este colectivo es el primero en adherir al trotskismo, como lo anuncia en la primera edición de su periódico Prensa

9 A principios de los años setenta la IV Internacional vive una lucha interna que la divide entre la Tendencia Mayoritaria Internacional (TMI) que orienta Ernest Mandel y la Tendencia Leninista Trotskista que orienta el argentino Nahuel Moreno. El principal debate de estas dos tendencias se origina por la caracterización que tienen sobre la lucha armada en América Latina, mientras el mandelismo ve unas fuerzas progresistas que rompen con el estalinismo.

10 Martha Cecilia García en su texto 'El presente es de lucha'. Una historia inconclusa, izquierdas políticas y sociales en Colombia hace un recorrido por estos colectivos que dieron origen al trotskismo en Colombia. 
Obrera $^{11}$. Espartaco hace una defensa de la táctica de guerra de guerrillas en América Latina e intenta crear un partido que sea la sección colombiana de la IV Internacional y si bien no puede concretar esta idea, cuenta con el apoyo de uno de sus dirigentes a nivel internacional, Ernest Mandel.

Grupo Marxista Internacionalista: conformado en 1973 con el liderazgo de Eduardo Mackenzie para contraponerse a las posiciones del Grupo Espartaco frente a la validez de la lucha armada como táctica revolucionaria en América Latina.

Bloque Socialista: conformado en 1971 por varios colectivos como Tendencia Socialista, Gaceta Obrera, Diario Latino y Comuneros ${ }^{12}$. Sus principales líderes son Ricardo Sánchez, Camilo González y Luis Carlos Valencia. Estos colectivos inician un proceso de unidad por iniciativa de Tendencia Socialista que se organiza en torno de la revista Crítica Marxista que aparece entre 1971 y 1972, varias de las publicaciones de esta revista son compiladas en el libro La política revolucionaria en Colombia, una aproximación crítica. Este libro contiene varios artículos sobre el capitalismo en Colombia, el movimiento obrero, el movimiento estudiantil y diversas críticas al programa del Partido Comunista Colombiano que es caracterizado como "etapista", también se expresan simpatías por la Revolución Cubana, se defiende la táctica electoral abstencionista y se incluyen artículos sobre el arte y la literatura desde una perspectiva marxista, varios de los cuales han aparecido anteriormente en el periódico Revolución Socialista. Es de resaltar, el texto elaborado por Tendencia Socialista, La revolución mundial y el revisionismo en Colombia ${ }^{13}$, en el que se hace una crítica al estalinismo a través del análisis de los documentos preparatorios del XI Congreso del PCC. El Bloque Socialista si bien no surge como una organización trotskista, adhiere a esta corriente y establece una relación con el exilio del Partido Socialista de los Trabajadores de Argentina en Bogotá, de esta manera es conducido por el dirigente argentino Nahuel

11 ¿De dónde venimos, hacia dónde vamos, hacia dónde debemos ir? (Medellín: Proletarización, 1975).

12 El abogado Édgar Ospina, quien fuera militante del Bloque Socialista, manifestó en una entrevista realizada en diciembre de 2015 que este bloque agrupaba alrededor de 500 integrantes en todo el país para el ańo 1977, cuando fundan el Partido Socialista de los Trabajadores.

13 Artículo publicado en la revista Crítica Marxista, No. 15 (1972). 
Moreno y lo acompañan en su lucha contra la resolución sobre América Latina que ha votado el IX Congreso de la IV Internacional, la cual hace una caracterización de la Revolución Cubana como una experiencia que valida la táctica de la lucha armada a nivel continental y que rompe con las directrices del estalinismo.

Unión Socialista Revolucionaria (USR): escisión del Bloque Socialista que surge en 1974, después de la III Reunión Nacional en la que se asumen tesis organizativas cercanas al leninismo. La USR sostiene que el centralismo democrático impide la conformación de un partido de masas y decide acercarse a los Comandos Camilistas para crear una agrupación que permita esta posibilidad

Comandos Camilistas: corriente de activistas creada a finales de 1969 y que reivindica algunas orientaciones del Frente Unido de Camilo Torres Restrepo, pero que reúne un grupo llamado Testimonio y a diversos grupos que provienen del anarquismo. Su principal escenario es la Universidad Nacional de Bogotá y plantea simpatías con la Revolución Cubana. En un reciente artículo se sostiene que "algunos militantes empezaron a ver las limitaciones del bagaje programático y político del pensamiento camilista y viraron sus ojos ávidos de respuestas teóricas y políticas más convincentes y eficaces hacia la corriente política agrupada en la IV Internacional fundada por León Trotsky"14.

Liga Obrera Comunista (LOC): surge a finales de 1974 como una ruptura del Bloque Socialista, al que acusaban de tener posiciones centristas, cuando se discutía la adhesión a la IV Internacional. Fueron aliados del Grupo Espartaco y de Comandos Camilistas en la conformación de la Liga Comunista Revolucionaria en agosto de 1977.

Estos colectivos se conforman en las universidades y muchos de ellos reflejan las complejidades de la vida urbana y las inquietudes intelectuales de

14 Jesús Rafael Bolívar, "Una historia de los Comandos Camilistas", Revista Cedotic Vol. 2, No. 3 (2017). http://investigaciones.uniatlantico.edu.co/revistas/index.php/CEDOTIC/article/view/1878 (Fecha de consulta: 30 de abril de 2017). 
una juventud formada con la experiencia de Mayo del 68. Sin embargo, en sus discursos es recurrente la idea de los programas obreros como ejes de los procesos revolucionarios, pues si bien su inserción en la clase trabajadora es mínima, su preocupación por entender el marxismo más allá de los manuales de los partidos comunistas los lleva a distanciarse de la mayor parte de la izquierda política de la época que ve en el movimiento campesino el sector con más dinamismo en los procesos de transformación social. Esta "proletarización” de estos colectivos estudiantiles provenientes en buena medida de la clase media tiene su explicación en la relación dialéctica y no mecánica que existe entre la formación de la conciencia de clases y la existencia material ${ }^{15}$. Parte de estas discusiones serán retomadas por los colectivos socialistas revolucionarios que aspiran a hacer una lectura marxista del proceso revolucionario por fuera de los manuales soviéticos.

\section{CONVERGENCIAS: EL MOVIMIENTO ESTUDIANTIL DE 1971}

Como se mencionó anteriormente, los colectivos socialistas mantienen una posición unificada en el movimiento estudiantil, en particular frente a la coyuntura de 1971, al tiempo que saldan sus divergencias políticas. Estas discusiones entre las corrientes políticas sirven como elemento cohesionador de los colectivos socialistas que libran luchas tendenciales en su interior, pero que se presentan de manera coordinada en las reuniones nacionales estudiantiles. En estos espacios los colectivos socialistas revolucionarios son calificados como "trotskistas", pues no solo tienen una posición unificada frente a la coyuntura política, sino que son una crítica a los modelos de revolución que defienden sus principales contendores: Jupa y Juco.

En julio de ese año, Tendencia Socialista -que proviene del núcleo estudiantil que se expresa a través de la revista Crítica Marxista en la Universidad del Valle- publica el Manifiesto socialista a los estudiantes colombianos en el que reúnen buena parte de las tesis que defienden estos colectivos.

15 Omar Acha, "E.P. Thompson, un marxista contra el marxismo como materialismo histórico", Revista Rey Desnudo No. 3 (2013): 323. 
Dos ideas atraviesan el pensamiento de los socialistas revolucionarios, la primera es el carácter de clase de la universidad como institución que "reproduce" el sistema capitalista y la segunda es la valoración del Programa Mínimo de los Estudiantes Colombianos como un conjunto de consignas reformistas que deben estar al servicio de la causa revolucionaria y no ser un objetivo en sí mismo. En ese momento Tendencia Socialista plantea que el movimiento estudiantil ha pasado de una etapa ofensiva, en la que los estudiantes han logrado a través de la movilización cuestionar las políticas educativas del gobierno de Misael Pastrana, a una etapa defensiva en la que hay dispersión de los estudiantes debido a la represión estatal y a los cierres de muchas universidades.

Así, el Manifiesto plantea la necesidad de un cambio táctico en la orientación de las luchas estudiantiles que implica "concretar la exigencia de reapertura de las universidades - diferente de normalidad académica- que nos facilitara, ya con los estudiantes, cumplir las tareas y seguir luchando ${ }^{16}$. Para marzo de 1972 el Bloque Socialista publica en el periódico Revolución Socialista el "Manifiesto de los socialistas a los estudiantes del distrito" en el que dan cuenta de los reveses que ha sufrido la lucha estudiantil, atribuidos a la táctica de enfatizar la lucha en el cogobierno:

"La universidad burguesa continúa viviendo su constante crisis. Los grupos pequeño-burgueses, se han enredado en la oscura madeja del cogobierno. Reclaman a gritos un apoyo para su gestión burocrática, mientras recorren las calles como lobos hambrientos en busca de un 'sufragio' más. 'Revolucionaria' se ha reducido a la curul de concejal en cualquier municipio colombiano. Han sido asimilados definitivamente por la política burguesa" ${ }^{17}$.

En una investigación realizada por Acevedo Tarazona y González Rey ${ }^{18}$ se

16 Tendencia Socialista. Manifiesto socialista a los estudiantes colombianos (Cali, 1971).

17 Bloque Socialista. "Manifiesto de los socialistas a los estudiantes del distrito". Revolución Socialista No. 2 (1972).

18 Álvaro Acevedo Tarazona y Diana Crucelly González Rey, "Movilización y protesta estudiantil en Colombia (1971). Una lectura desde la organización gremial por el cogobierno universitario y la 
muestra cómo la contradicción principal está en el punto del cogobierno, pues mientras Tendencia Socialista ve en esta reivindicación la concreción del etapismo y de la conciliación de clases de los grupos maoístas, Jupa ve un avance en la lucha estudiantil en concordancia con sus tesis de nueva democracia:

"La contraposición de ideas en el mismo seno de las organizaciones estudiantiles llevó a una serie de discusiones internas, aunque predominó la posición promovida por la Juventud Patriótica referida a la construcción de una cultura revolucionaria en la propia lucha estudiantil, sobre todo porque se justificaba la búsqueda de un cogobierno de la universidad como un paso relevante en la construcción de dicha cultura. Sobre la base de esta tesis, cuando se consiguió el cogobierno en la Universidad Nacional, en noviembre de 1971, y en la Universidad de Antioquia, en enero de 1972, se anunció uno de los mayores triunfos del estudiantado colombiano en la historia del movimiento. No obstante, su efímera existencia comprende también una de sus mayores decepciones. Después de unos pocos meses de implementación del experimento del cogobierno a finales de mayo de 1972 volvieron los rectores del gobierno y con ellos la suspensión de la participación ampliada de estudiantes y profesores en los consejos superiores" ${ }^{19}$.

Para los colectivos agrupados en el Bloque Socialista, el balance es también negativo. A finales de 1976 en un artículo publicado en la revista Ideología y Sociedad por Ibón Lebot, una vez más señalan que el énfasis en la táctica del cogobierno impulsado por Jupa es el responsable del reflujo del movimiento estudiantil a partir de 1972:

"La liquidación brutal de las experiencias de la cogestión, las expulsiones sistemáticas y calculadas de militantes, etc. alcanzan su finalidad: el movimiento estudiantil desquebrajado, desorientado

memoria de protagonistas y testigos" Anuario de Historia Regional y de las fronteras, Vol. 16, No. XVI (2011). http://revistas.uis.edu.co/index.php/anuariohistoria/article/view/2492/3983 (Fecha de consulta: 22 de julio de 2016).

19 Álvaro Acevedo Tarazona y Diana González Rey, Movilización y protesta estudiantil..., p. 233-234. 
y dividido, pasa por una etapa difícil. La mayoría de los estudiantes, decididos por el viraje tomado por los acontecimientos después de las esperanzas de 1971 se desinteresan en la agitación que los grupos politizados buscan mantener en las universidades" 20 .

Más allá de los balances, para los socialistas revolucionarios el paro de 1971 significa la posibilidad de agruparse y de pasar de colectivos estudiantiles dispersos en cada universidad, a establecer formas de coordinación y, más adelante, a construir una propuesta política más allá de la coyuntura y del movimiento estudiantil. Precisamente el movimiento estudiantil de 1971 es la coyuntura política en la que se propician los contactos de todas las experiencias del socialismo revolucionario y se propician encuentros paralelos para coordinar su accionar en las asambleas, llamados por ellos 'encuentros de emergencia', en los que se reúnen para discutir la posibilidad de construir una organización política. El Bloque Socialista se conforma en medio de las movilizaciones estudiantiles que desde el 25 de enero de 1971 se habían iniciado en la Universidad del Cauca y que tuvieron su expresión más significativa en el conflicto estudiantil en la Universidad del Valle, que llevaría a la jornada del 26 de febrero en la que fueron asesinados varios estudiantes durante las protestas. Al calor del Paro Nacional Estudiantil de 1971, estos grupos coinciden en las discusiones contra Jupa del MOIR y Juco del PCC y deciden conformar el Bloque Socialista por iniciativa del colectivo Crítica Marxista de la ciudad de Cali. Inicialmente Tendencia Socialista tiene la iniciativa de crear el Comité de Diálogo en el que confluyen el Grupo Espartaco, Gaceta Obrera, Comuneros y Diario Latino. De estas agrupaciones, Espartaco es la única que se reivindica como trotskista y que mantiene desde entonces una relación con la IV Internacional, de la que era su sección oficial en Colombia.

Las diferencias entre Espartaco y Tendencia Socialista marcaron los primeros debates del Bloque Socialista. Espartaco quedaría por fuera, pero continuaría siendo la principal referencia de discusión política de quienes aspiraban a ser parte de la IV Internacional. Así, el Bloque Socialista surge

20 Ibón Lebot, "El movimiento estudiantil durante el Frente Nacional (1958-1974)”, Ideología y Sociedad No. 19 (1976). 
de la fusión de los colectivos Tendencia Socialista, Diario Latino, Gaceta Obrera y Comuneros. Este proceso se hace a través de tres encuentros llamados Reuniones de Emergencia que se realizaron entre los ańos de 1972 y 1974. El abogado Édgar Ospina, quien fuera militante del Bloque Socialista, manifestó en una entrevista realizada en diciembre de 2015, que "en la Primera Reunión de Emergencia se llega a un acuerdo para publicar el periódico Revolución Socialista y se caracteriza al Bloque Socialista como un instrumento para la construcción del núcleo partidista. Se define que se realizará una conferencia decisoria en la que se debe adoptar un programa con el fin de centralizar el accionar político"21.

En la Segunda Reunión Nacional de Emergencia realizada el 26 de agosto de 1972 se inicia la discusión acerca del movimiento campesino, que por ende, llevaría a una caracterización de la lucha armada. Se debe anotar que estos eran colectivos universitarios urbanos y sectores del movimiento obrero y docente que no tenían ninguna vinculación con el movimiento campesino, que en ese momento era uno de los principales escenarios de la izquierda política en Colombia. Dos documentos importantes surgen de esta reunión: la "Declaración Política" y "La lucha de clases en el campo y la política de los socialistas". En el primer documento se plantea la tesis de revolución ininterrumpida para diferenciarse de la revolución por etapas que planteaban el PCC, el MOIR y demás grupos marxista-leninistas; en el segundo documento se manifiesta que el movimiento campesino no ha comprendido la necesidad de la lucha por el socialismo ${ }^{22}$.

Antes de la Tercera Reunión de Emergencia se realizan dos reuniones plenarias en Bogotá (diciembre de 1972) y Cali (abril de 1973) en las que se logran discutir muchas de las diferencias internas. En uno de los materiales preparatorios de la reunión plenaria de Cali, "La situación y los rumbos de la lucha revolucionaria en Colombia", se aborda el triunfo de Vietnam para hacer una crítica a la táctica guerrillera y combatir las posiciones foquistas que venían avanzando en Espartaco, diciendo que la guerra de guerrillas se debe analizar en "el marco social en que actúa y de acuerdo a los propósitos

21 Entrevista a Ospina, Édgar, Cartagena, diciembre de 2015.

22 Bloque Socialista. Por un Partido Obrero, p. 68. 
de la revolución... aceptando la diferenciación social en su seno y en torno a un programa de carácter democrático y anticapitalista" ${ }^{23}$. En la Tercera Reunión Nacional de Emergencia realizada en 1974 afloran las diferencias ya no de manera teórica sino como expresiones organizativas. De hecho, esta reunión que tuvo su sesión inicial en enero de ese año, debió ser suspendida y retomada en el mes de junio. Para entonces, había ingresado al Bloque Socialista el colectivo Los Comuneros de Popayán y otros de Medellín, Pereira, Manizales y Pasto. También ingresó el Grupo Marxista Internacionalista (GMI) creado en Bogotá en 1973 — como ruptura de Espartaco- y que se había ligado a una minoritaria IV Internacional encabezada por el Socialist Work Party de Estados Unidos y el Partido Socialista de los Trabajadores de Argentina. El centro de las discusiones estaba en la Declaración Política y en particular, en la situación del movimiento campesino y la táctica de guerra de guerrillas:
"Toda la discusión en esta primera parte se centra en el temario y el orden en el que se debían abordar las discusiones. Un sector decía que en la organización había unidad ideológica y que lo fundamental era discutir los problemas organizativos. El otro sec- tor insistía en que no había unidad ideológica y, por lo tanto, era imprescindible abordar primero la discusión política y luego los problemas organizativos" 24 .

La segunda sesión de la Tercera Reunión de Emergencia se lleva a cabo en el mes de junio, pero en este intervalo se realizan dos reuniones distintas en las que se consolidan dos tendencias que-aunque abogan por la unidad del Bloque Socialista-, se preparan para la ruptura. En la primera reunión en Medellín del 11 al 14 de abril de 1974, se organiza una nueva fracción: USR. En la segunda reunión llevada a cabo en Cali, los días 25 y 26 de mayo de 1974, se encuentra la mayoría de los colectivos y se advierte de la división del Bloque Socialista.

En esta tercera reunión, que deja al margen a la USR, el Bloque Socialista define un programa que si bien no se proclama como trotskista de manera

23 Bloque Socialista. Por un Partido Obrero.

24 Entrevista a Ospina... 
literal, reúne todas las características para adherirse a esta corriente. Las organizaciones socialistas que han quedado al margen del Bloque Socialista señalan que en estas definiciones hay una "desviación obrerista", pues en los distintos documentos de esta Tercera Reunión de Emergencia se hace una crítica a la "desviación campesinista" que trae el Bloque Socialista, que ha apostado a varios de sus militantes en zonas campesinas. Estos documentos fueron compilados en el folleto Por un Partido Obrero Socialista. Tesis y documentos del Bloque Socialista ${ }^{25}$, su tesis central reúne las principales ideas del pensamiento trotskista: revolución permanente y no por etapas, programa de transición y necesidad de construir un partido revolucionario, así como el distanciamiento de la lucha armada en favor de la lucha de masas:

"El socialismo tiene que aclarar ante las masas que ninguna reforma constitucional ni ninguna concesión del régimen podrá cambiar su sustancia represiva y dictatorial; que solamente por medio de la destrucción del actual régimen político en virtud de la lucha directa de las masas para sustituirlo por la dictadura del proletariado será posible garantizar la satisfacción de los intereses de los sectores democrático-revolucionarios y garantizar el efectivo paso a la sociedad sin clases, a través del cumplimiento de las tareas democráticas de la revolución así como de sus tareas propiamente socialistas" 26 .

El Bloque Socialista entraría en relaciones con un sector de la IV Internacional a través de un grupo de exilados del Partido Socialista de los Trabajadores en Bogotá y desarrollaría una discusión con Espartaco y otras agrupaciones que habían estado al principio cerca de este proceso, en torno a la caracterización de la lucha armada en Colombia y en América Latina ${ }^{27}$.

\section{Divergencias: la lucha armada en América Latina}

Una vez conformado el Bloque Socialista se inicia un nuevo proceso uni-

25 Bloque Socialista. Por un Partido Obrero, p. 13.

26 Bloque Socialista. Por un Partido Obrero, p. 57.

27 Martín Mangiantini, El exilio trotskista en Colombia (1976-1982) (La Plata: Universidad Nacional de La Plata, 2012). 
tario entre Espartaco, Comandos Camilistas y la Liga Obrera Comunista. El Bloque Socialista ya se había adherido a la corriente morenista que mantenía una posición crítica frente a la dirección mayoritaria de la IV Internacional.

En Argentina, la sección oficial de la IV Internacional, el Partido Revolucionario de los Trabajadores, se había dividido en 1970 en dos fracciones: el PRT-La Verdad dirigido por Hugo Bressano, conocido con el seudónimo de Nahuel Moreno, y el PRT-El Combatiente dirigido por Mario Roberto Santucho, quien había conformado el Ejército Revolucionario del Pueblo como su brazo armado ${ }^{28}$. Para 1974 tras la realización del X Congreso de la IV Internacional, se avala la posición de Santucho en Argentina, lo que abre una lucha entre dos fracciones: la Tendencia Leninista Trotskista (TLT) liderada por Moreno y la Tendencia Mayoritaria Internacional (TMI) liderada por Ernest Mandel. El principal debate de estas dos tendencias se originó por la caracterización que tenían sobre la lucha armada en América Latina.

En Colombia los colectivos socialistas revolucionarios adoptaban posiciones divergentes frente a la lucha guerrillera que a inicios de los ańos setenta ya tenía importante presencia en los movimientos sociales, en especial en el movimiento campesino. Espartaco y Comandos Camilistas mostraban simpatías por algunas corrientes guerrilleras que eran vistas como progresistas al cuestionar las políticas de conciliación de clases del Partido Comunista. Por su parte, la IV Internacional hacía presencia por doble vía en el país, por un lado con las visitas de los dirigentes de la TMI y, por otro lado, por la llegada a Bogotá en 1976 de varios dirigentes de la TLT exilados de Argentina, entre ellos Nahuel Moreno, quien había fundado en 1972 el Partido Socialista de los Trabajadores (PST) como ruptura definitiva con el PRT de Santucho.

El exilio de los dirigentes de la TLT empalmó con el Bloque Socialista, mientras la TMI tenía en Espartaco y Comandos Camilistas sus principales aliados. Así, la discusión sobre la caracterización de la lucha armada en

28 Martín Mangiantini, El trotskismo y el debate en torno a la lucha armada. Moreno, Santucho y la ruptura del PRT (Buenos Aires: Controversias, 2014). 
América Latina llega al naciente trotskismo colombiano de manera directa. Esta discusión se puede ver en un folleto llamado Historia. Material didáctico correspondiente al bachillerato acelerado del Instituto Uriburu ${ }^{29}$, que fue enviado desde Bogotá a Buenos Aires en mayo de 1977 y que en apariencia contenía un manual de historia sobre 'La acción de la Iglesia Católica en el período de la independencia y de la organización nacional', pero a partir de la cuarta página mecanografiada aparece una serie de documentos que el Bloque Socialista enviaba al Partido Socialista de los Trabajadores de Argentina, que en esos momentos resistía la persecución del gobierno de la Junta Militar que dirigía el general Jorge Rafael Videla, tras el golpe de estado en marzo de 1976.

Como este folleto, muchos documentos eran mimetizados para evadir el control de los organismos estatales, pero este contenía no solo un informe de la visita de Ernest Mandel a Colombia sino toda una discusión acerca de la caracterización de la lucha armada en América Latina. El documento también nos revela la lucha fraccional que impedía la construcción de un proyecto común entre los trotskistas colombianos.

La IV Internacional había realizado su X Congreso Mundial en 1974 que reconocía al Grupo Espartaco como sección oficial. En este congreso, la Tendencia Mayoritaria Internacional (TMI) veía en la lucha guerrillera expresiones políticas por fuera del estalinismo, correspondientes al desarrollo del capitalismo tardío en América Latina y en la lucha del movimiento campesino; mientras la Tendencia Leninista Trotskista hacía una crítica a la lucha armada ${ }^{30}$.

El primero de los documentos que contiene el folleto es 'Autocrítica de la TMI sobre América Latina'. Uno de los acuerdos posteriores al IX Congreso Mundial era realizar una autocrítica por parte de la TMI en su caracterización sobre la Revolución Cubana y las lecciones que debía sacar el movimiento revolucionario de América Latina al respecto. La TLT sostiene en su informe:

29 Bloque Socialista. Boletín Político Internacional (Bogotá, 1977).

30 Martín Mangiantini, El trotskismo y el debate en torno a la lucha armada, p. 68. 
"Bajo la perspectiva de una guerra civil prolongada cuyo eje principal es la guerrilla rural (...) el problema de las ligazones de la guerrilla con las masas es el problema vital. Así, si bien es cierto que en la resolución se hace una crítica del guerrillerismo, su debilidad es la resultante de la orientación general del texto, a tal punto que disminuye las críticas hechas anteriormente a la concepción guerrillerista de otros textos de la internacional" 31 .

Para la TLT el influjo de la Revolución Cubana y la crisis que causó en los partidos comunistas había llevado a una caracterización errónea del proceso, pero el principal error emanaba de las conclusiones que se habían sacado en torno a lo que representaba la lucha armada para los procesos revolucionarios de América Latina:

"Bajo el impacto de esta victoria y estimulada por su ejemplo, una nueva generación de militantes revolucionarios aparecía en todo el continente. Rompían empíricamente con un pasado de concesiones, de inacción, de renunciamientos y de traiciones que encarnaban los Partidos Comunistas de América Latina. Un pasado que había conducido a la clase obrera y al campesinado pobre a no ser más que fuerzas pasivas de apoyo a las operaciones políticas de sectores burgueses, o masas de maniobra para los movimientos políticos de la pequeña burguesía. La combinación de estos dos factores, inestabilidad sociopolítica estructural e influencia de la Revolución Cubana, particularmente sobre la vanguardia, determinó el contexto a partir del cual fue elaborada la 'Resolución sobre AL' del IX Congreso Mundial"32.

Para la TLT había que mirar el viraje que había dado la Revolución Cubana, sobre todo después de la llamada Conferencia de la Organización Latinoamericana de Solidaridad (OLAS) ${ }^{33}$ realizada en agosto de 1967 en Cuba. Para la TLT: ta: 25 de enero de 2016). 
"No habíamos comprendido que la conferencia de las OLAS, después de la cual no se hizo nada importante ni concreto, marcaba el fin de una época para la revolución cubana. Lo que ocurrió fue la tentación de desvincularse de la lucha revolucionaria continental, y no de vincularse más a ella. Nuestras estimaciones de las relaciones de fuerzas internas en La Habana, sobre la que se fundaban nuestras posiciones, eran falsas. La salida del Che de Cuba en 1966 reflejaba un cambio cualitativo de dichas relaciones de fuerzas en el seno de la dirección cubana. No lo comprendimos. He aquí una segunda fuente de errores de análisis cuando el IX CM dado el considerable papel que había tenido la dirección cubana en el surgimiento de un nuevo movimiento revolucionario, y dado el prestigio y el peso de dicha dirección, ese viraje iba a tener consecuencias cuya lógica se nos escapó" 34 .

En este contexto, se realiza una segunda discusión entre el Bloque Socialista y las otras organizaciones oficiales o simpatizantes de la IV Internacional que habían iniciado un proceso de unificación. En el segundo artículo del folleto Informe para la dirección de la Tendencia Bolchevique sobre la visita del compañero Mandel a Colombia, en noviembre de 1976 se precisa esta discusión.

Ernest Mandel había llegado a reunirse con los cuatro sectores, pero su intención era hacerlo por separado. Para Mandel, la unidad de estas organizaciones socialistas era en dos momentos, primero se debían unificar las tres organizaciones de la TMI (Espartaco, Comandos Camilistas y Liga Obrera Comunista) y después se haría la unidad con el Bloque Socialista, por supuesto, esto dependía de que se avanzara en las discusiones políticas y organizativas entre la TMI y la TLT. El folleto describe:

"En un local pequeño se reunieron, un tanto apretados, aproximadamente 250 cros, la intervención con la que abrió Mandel fue fuertemente fraccionalista, contra la TB y fundamentalmente

34 Bloque Socialista. Boletín Político Internacional, p. 44-45. 
contra el BS... Moreno no tenía pensado intervenir, pero lo hizo porque Mandel aludió en forma directa a él y le aconsejó que lo hiciese... Habló en forma violentísima, denunciando el carácter santo con que Mandel quería revestir a sí mismo y a la TMI, creyendo que estaba hablando con ignorantes y precisando que las divergencias fraccionales no habían surgido porque la FLT se negaba a captar a los dirigentes de las huelgas en Europa, sino por la estrategia guerrillera que la TMI impuso para AL"35.

En medio de estas discusiones y ante la división de la IV Internacional se hace imposible el proceso unitario entre las expresiones mandelistas y morenistas de la lucha entre estas dos corrientes en Colombia. Al mismo tiempo el país avanzaba hacia un proceso de movilizaciones que desembocaría en el Paro Cívico de 1977 y, con este ascenso en las luchas, el Bloque Socialista se propone convertirse en partido político, dejando atrás los esfuerzos unitarios entre los colectivos socialistas revolucionarios del país.

Los colectivos pertenecientes a la TMI intentaron unificarse entre 1976 y 1977, “esta fusión se llevó a cabo en Barranquilla, entre el 12 y el 15 de agosto de 1977, durante el congreso fundacional de la Liga Comunista Revolucionaria (sección colombiana oficial de la IV Internacional)"36. Por su parte, el Bloque Socialista decidió conformar el Partido Socialista de los Trabajadores en septiembre de 1977, diez días después de la realización del Paro Cívico Nacional.

\section{A MANERA DE CIERRE}

El trotskismo en Colombia es tardío respecto a otros países de América Latina y su incidencia en el movimiento social no ha sido constante, fue protagonista del movimiento estudiantil del 71 a través de los colectivos socialistas revolucionarios y pocos días después del Paro Cívico del 77 se funda el Partido Socialista de los Trabajadores, PST, la primera experiencia partidaria trotskista del país. Por su parte, el Grupo Espartaco, la Liga

36 Bloque Socialista. Boletín Político Internacional, p. 51. 
Obrera Comunista y los Comandos Camilistas -impulsados por el dirigente Ernest Mandel de la IV Internacional- inician un proceso de fusión a finales de 1976, que da como resultado la formación de la Liga Comunista Revolucionaria, LCR, en agosto de 1977 en un evento realizado en Barranquilla. La LCR se convierte de esta manera en la sección oficial de la IV Internacional en Colombia.

En 1978, la LCR y el PST -junto a la Organización Comunista Ruptura, de origen maoísta- se encontrarían de nuevo en la coyuntura electoral, lanzando la candidatura de Socorro Ramírez a nombre de la Unión Obrera Socialista, un frente socialista que hace un llamamiento a la unidad de la izquierda, buscando un acuerdo con el Partido Comunista y el MOIR, que al final apoyaron candidaturas con sectores que rompían con los partidos tradicionales.

Poco tiempo después de la conversión del Bloque Socialista en Partido Socialista de los Trabajadores, un sector se escinde, recogiendo buena parte de la militancia mandelista de otros colectivos. En menos de un año se produce la primera ruptura del PST como resultado de la adopción del centralismo democrático que exigía mayores niveles de disciplina en una militancia que provenía en su mayoría del movimiento estudiantil y de experiencias de colectivos que se habían construido en el activismo universitario. Los viejos debates del Bloque Socialista con los otros colectivos del socialismo revolucionario emergen, el principal de ellos, la lucha armada en América Latina.

Los disidentes conforman el Partido Socialista Revolucionario, PSR, el mismo nombre que tuviera el primer partido de izquierda en Colombia en los años veinte. Contrario al PST, el PSR no tenía un régimen de centralismo democrático y tenía una caracterización distinta de corrientes guerrilleras como el Movimiento 19 de Abril (M-19) y el Ejército de Liberación Nacional (ELN) que para el PSR eran expresiones políticas de izquierda que estaban por fuera del estalinismo y por tanto, era viable un proceso de unidad política con estas fuerzas. En el PSR confluye un buen número de militantes de los colectivos como Comandos Camilistas, la URS, la LOC y el Grupo Espartaco. 
En 1979 el naciente PST conformó la Brigada Simón Bolívar a través de la cual envió a un numeroso grupo de militantes a intervenir en la Revolución Nicaragüense, la Brigada entraría en contradicción con el Frente Sandinista de Liberación Nacional (FSLN) por el carácter que debía tener este proceso revolucionario. Mientras el FSLN, apoyado por el líder cubano Fidel Castro, planteaba que no se podía expropiar, la Brigada sostenía que la Revolución Nicaragüense solo podía sostenerse si llevaba a cabo este proceso. El FSLN decide entonces expulsar a la Brigada con el apoyo del Secretariado Unificado de la IV Internacional. Para 1982 la TLT -ahora convertida en Fracción Bolchevique- decide fundar en Bogotá una ruptura de la IV Internacional: la Liga Internacional de los Trabajadores (LIT), como respuesta a su posición de apoyo a la expulsión de la Brigada Simón Bolívar. La fundación de la LIT y el sostenimiento de su dirección política en Colombia implicó una tarea mayúscula para el PST, pero también la posibilidad de consolidar su formación partidaria con la presencia de varios dirigentes internacionales del trotskismo.

Pero los trotskistas colombianos volverían a coincidir en 1984 en el Movimiento Político A Luchar, aunque con diferencias frente al papel que desempeñaba el ELN dentro del mismo. Mientras el PST criticaba la hegemonía que tenía la dirección guerrillera en A Luchar ${ }^{37}$, el PSR decidía disolverse en este movimiento, aflorando así, una vez más, la vieja discusión entre el Bloque Socialista y los grupos afines al mandelismo. Para finales de los años ochenta, el PSR dejará de existir y buena parte de su militancia se sumará a las filas de corrientes políticas liberales, mientras el PST mantiene una pequeña influencia en el movimiento social que le permite tener presencia en la dirigencia de la Central Unitaria de los Trabajadores, CUT, y en la Federación Colombiana de Educadores, Fecode.

Como se puede observar, fueron varios los momentos de convergencia del trotskismo en Colombia: el Paro Universitario de 1971, la coyuntura electoral de 1978, el Movimiento Revolucionario A Luchar; así como los esfuerzos de unificar colectivos políticos que tenían orígenes diversos, como

37 Nahuel Moreno, Carta al PST(C) sobre A Luchar. http://www.izquierda.info/moreno/50_NM.pdf (Fecha de consulta: 2 de mayo de 2016). 
fuera la conformación del Bloque Socialista y de la Liga Comunista Revolucionaria. Pero también se dieron otras discusiones que generaron divergencias, entre ellas la lucha armada y el carácter que debía tener la organización revolucionaria. Los primeros colectivos socialistas revolucionarios surgen en un momento en el que la lucha armada es acogida por la mayor parte de las fuerzas de izquierda en Colombia y si bien estos colectivos no participan de manera directa en la lucha armada, aunque algunos tienen simpatías, las distintas caracterizaciones darían al traste con la unidad. A lo anterior se debe agregar la presencia permanente de algunos dirigentes importantes de la IV Internacional que atravesaba una discusión por la caracterización de la lucha armada en América Latina.

Así, en este proceso de revisión de los orígenes del trotskismo en Colombia, se evidencia que el desarrollo de la izquierda política en Colombia -y en particular de aquellas organizaciones que compartieron la táctica de guerra de guerrillas- no solo se puede ver como una respuesta al régimen político particular del Estado colombiano que no permitió la participación política de terceras fuerzas, sino también es resultado de las tendencias internacionales que llegaron al país tras los triunfos revolucionarios de China y Cuba.

\section{BibLIOGRAFÍA}

\section{Fuentes primarias}

Bloque Socialista. Boletín Político Internacional. Bogotá, 1977.

Bloque Socialista. "Manifiesto de los socialistas a los estudiantes del distrito”. Revolución Socialista Año 1 No. 2 (1972).

Bloque Socialista. Por un Partido Obrero Socialista. Tesis y documentos del Bloque Socialista. Bogotá, 1975.

Caidedo, Jaime. "Movimiento juvenil, movimiento estudiantil y unidad popular". En documentos teóricos internos al movimiento estudiantil 1971, compilado por Julio Puig y Olga Zuluaga. Medellín: Universidad de Antioquia, 1974. https://es.scribd.com/document/52353488/Juventud-Comunista-Movimiento-juvenil-movimiento-estudiantil-y-unidad-popular.

Entrevista a Ospina, Édgar. Cartagena, diciembre de 2015.

Juventud Patriótica. "'Gran lucha revolucionaria de la juventud”". Tribu- 
na Roja No. 1 (1971). http://tribunaroja.moir.org.co/GRAN-LUCHA-REVOLUCIONARIA-DE-LA.html.

Lebot, Ibón. "El movimiento estudiantil durante el Frente Nacional (19581974)”. Ideología y Sociedad No. 19 (1976).

Moreno, Nahuel. Carta al PST(C) sobre A Luchar. http://www.izquierda. info/moreno/50_NM.pdf

Tendencia Socialista. Manifiesto socialista a los estudiantes colombianos.

Cali, 1971. https:/www.scribd.com/fullscreen/52353509?access_ key=key-1ew5jkm06i1d5sc2hqon.

\section{Fuentes secundarias}

Acevedo Tarazona, Álvaro. 1968. Historia de un acontecimiento. Utopía y revolución en la universidad colombiana. Bucaramanga: Ediciones Universidad Industrial de Santander, 2017.

Acevedo Tarazona, Álvaro. "Ideología revolucionaria y sociabilidad política en los grupos universitarios maoístas de los años 60 y 70 en Colombia”. Historia Caribe Vol. XI, No. 28 (2016): 149-175.

Acevedo Tarazona, Álvaro. Memorias de una época: el movimiento estudiantil en Colombia en los ańos sesenta y setenta del siglo XX. Bucaramanga: Universidad Industrial de Santander, 2016.

Acevedo Tarazona, Álvaro y Diana Crucelly González Rey. “Movilización y protesta estudiantil en Colombia (1971). Una lectura desde la organización gremial por el cogobierno universitario y la memoria de protagonistas y testigos". http://revistas.uis.edu.co/index.php/anuariohistoria/article/view/2492/3983

Acha, Omar. "E.P. Thompson, un marxista contra el marxismo como materialismo histórico”. Revista Rey Desnudo, Año II, No. 3 (2013): $1-22$.

Almeyda, Clodomiro. "OLAS y crisis política en América Latina”. Estudios Internacionales, Vol. 8, No. 32 (1975): 123-127. https://es.scribd. com/document/340059568/19241-58467-1-PB

Bensaid, Daniel. Trotskismos. Barcelona: Editorial Viejo Topo, 2007. Bolívar, Jesús Rafael. "Una historia de los Comandos Camilistas". Revista Cedotic, Vol. 2, No. 3 (2017). http://investigaciones.uniatlantico. edu.co/revistas/index.php/CEDOTIC/article/view/1878.

¿De dónde venimos, hacia dónde vamos, hacia dónde debemos ir? Medellín: Proletarización, 1975. 
García, Martha Cecilia. 'El presente es de lucha'. Una historia inconclusa, izquierdas políticas y sociales en Colombia. Bogotá: Cinep, 2009.

Jaramillo Vélez, Rubén. Colombia, la modernidad postergada. Bogotá: Argumentos, 1998.

Mangiantini, Martín. El exilio trotskista en Colombia (1976-1982). La Plata: Universidad Nacional de La Plata, 2012.

Mangiantini, Martín. El trotskismo y el debate en torno a la lucha armada. Moreno, Santucho y la ruptura del PRT. Buenos Aires: Controversias, 2014.

Molano, Frank. "El campo es leña seca lista para arder. La Liga Marxista Leninista de Colombia, 1971-1982". Anuario Colombiano de Historia Social y de la Cultura, Vol. 44, No. 2 (2017): 137-170.

Molano, Frank. El imaginario maoísta (1965-1982). Como mentalidad revolucionaria en la izquierda colombiana. Bogotá: Universidad Nacional de Colombia, 2004.

Moreno, Nahuel. ¿Partido leninista o partido mandelista? Buenos Aires: Grupo Socialista Guernica, 2001.

Tendencia Socialista. "La revolución mundial y el revisionismo en Colombia”. Critica Marxista, No. 15 (1972).

Para citar este artículo: Acevedo Tarazona, Álvaro y Patiño Romero, Franklin. "Orígenes del Trotskismo en Colombia: de los Colectivos Socialistas Revolucionarios al Bloque Socialista (1971-1977)", Historia Caribe Vol. XIV No. 34 (Enero-Junio 2019): 123-149. DOI: http://dx.doi. org/10.15648/hc.34.2019.4 